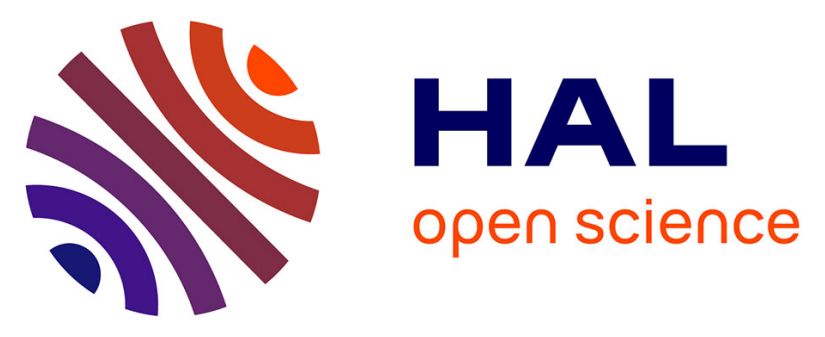

\title{
Point-of-care ultrasound in intensive care units: assessment of 1073 procedures in a multicentric, prospective, observational study
}

Laurent Zieleskiewicz, Laurent Muller, Charlotte Arbelot, Pierre-Marie

Bertrand, Belaid Bouhemad, Bernard Cholley, Didier Demory, Serge

Duperret, Jacques Duranteau, Christophe Guervilly, et al.

\section{To cite this version:}

Laurent Zieleskiewicz, Laurent Muller, Charlotte Arbelot, Pierre-Marie Bertrand, Belaid Bouhemad, et al.. Point-of-care ultrasound in intensive care units: assessment of 1073 procedures in a multicentric, prospective, observational study. Intensive Care Medicine, 2015, 41 (9), pp.1638 - 1647. 10.1007/s00134-015-3952-5 . hal-01758771

\section{HAL Id: hal-01758771 \\ https://hal.umontpellier.fr/hal-01758771}

Submitted on 9 Nov 2018

HAL is a multi-disciplinary open access archive for the deposit and dissemination of scientific research documents, whether they are published or not. The documents may come from teaching and research institutions in France or abroad, or from public or private research centers.
L'archive ouverte pluridisciplinaire HAL, est destinée au dépôt et à la diffusion de documents scientifiques de niveau recherche, publiés ou non, émanant des établissements d'enseignement et de recherche français ou étrangers, des laboratoires publics ou privés. 


\section{Point-of-care ultrasound in intensive care units: assessment of 1073 procedures in a multicentric, prospective, observational study}

\author{
Laurent Zieleskiewicz \\ Laurent Muller \\ Karim Lakhal \\ Zoe Meresse \\ Charlotte Arbelot \\ Pierre-Marie Bertrand \\ Belaid Bouhemad \\ Bernard Cholley \\ Didier Demory \\ Serge Duperret \\ Jacques Duranteau \\ Christophe Guervilly \\ Emmanuelle Hammad \\ Carole Ichai \\ Samir Jaber \\ Olivier Langeron \\ Jean-Yves Lefrant \\ Yazine Mahjoub \\ Eric Maury \\ Eric Meaudre \\ Fabrice Michel \\ Michel Muller \\ Cyril Nafati \\ Sébastien Perbet \\ Hervé Quintard \\ Béatrice Riu \\ Coralie Vigne \\ Kathia Chaumoitre \\ François Antonini \\ Bernard Allaouchiche \\ Claude Martin \\ Jean-Michel Constantin \\ Daniel De Backer \\ Marc Leone
}

Take-home message: In the intensive care unit, the prevalence of point-of-care ultrasound was $55 \%$. Ultrasound was utilized for diagnostic assessment in $87 \%$ of cases and procedural guidance in $13 \%$ of cases; its use impacted diagnostic and therapeutic strategies in 84 and $69 \%$ of cases. Transthoracic echocardiography and lung ultrasound were routinely performed by intensivists. In contrast, ultrasound guidance for central venous line and arterial catheter placement remains unsatisfactory.
For the CAR'Echo and AzuRea

Collaborative Networks

c/o M. Leone, Département d'anesthésie et de réanimation, Hôpital Nord, Marseille, France.

Members of the CAR'Echo and AzuRea

Collaborative Networks are listed in the

Acknowledgments.
L. Zieleskiewicz $\cdot$ Z. Meresse ·

E. Hammad - F. Michel - C. Vigne .

F. Antonini - C. Martin · M. Leone (®) Service d'anesthésie et de réanimation, Hôpital Nord, Assistance Publique Hôpitaux de Marseille, Aix Marseille Université, Chemin des Bourrely, 13015 Marseille, France

e-mail: marc.leone@ap-hm.fr

\section{Muller $\cdot$ J.-Y. Lefrant}

Service des réanimations, pôle anesthésie réanimation douleur urgence, CHU Nîmes, Nîmes, France

\section{K. Lakhal}

Réanimation chirurgicale polyvalente, service d'anesthésie réanimation, Hôpital Laennec, CHU Nantes, Nantes, France 
C. Arbelot · O. Langeron

Réanimation chirurgicale polyvalente, département d'anesthésie et de réanimation, d'instruction des armées Saint Anne, Hôpital Pitié Salpétrière, AP-HP, Paris, France

P.-M. Bertrand

Service de réanimation, Centre hospitalier de Cannes, Cannes, France

B. Bouhemad

Département d'anesthésie et de réanimation, CHU Dijon, Dijon, France

B. Cholley

Service d'anesthésie réanimation, Hôpital Européen Georges Pompidou, AP-HP, Paris, France

D. Demory

Service Réanimation Polyvalente-USC, Hôpital Sainte Musse, Avenue Sainte Claire Deville, Toulon, France

\section{S. Duperret}

Réanimation chirurgicale, Hôpital CroixRousse, Université Claude Bernard, Lyon, France

\section{J. Duranteau}

Assistance Publique Hôpitaux de Paris, Service d'Anesthésie-Réanimation, Hôpitaux Universitaires Paris-Sud, Université Paris-Sud, Hôpital de Bicêtre, Le Kremlin-Bicêtre, France

\section{Guervilly}

Service de réanimation DRIS, Hôpital Nord, Aix Marseille Université, Marseille, France

C. Ichai · H. Quintard

Réanimation médico-chirurgicale, Hôpital

Saint Roch, CHU de Nice, Nice, France

\section{S. Jaber}

Département d'anesthésie et de réanimation

B, Hôpital Saint-Eloi Inserm U1046,

Université Montpellier 1, Montpellier,

France

\section{Y. Mahjoub}

Département d'anesthésie et de réanimation, CHU d'Amiens, Amiens, France

\section{E. Maury}

Assistance Publique Hôpitaux de Paris, Hôpital Saint Antoine, Service de Réanimation Médicale, Université Paris 06, Paris, France

\section{E. Meaudre}

Département d'anesthésie, Hôpital

Toulon, France

M. Muller

Réanimation et surveillance continue,

Centre Hospitalier Annecy-Genevois,

Annecy, France

C. Nafati

Service d'anesthésie et de réanimation,

Hôpital la Conception, Aix Marseille

Université, Marseille, France

S. Perbet · J.-M. Constantin

Département de Médecine Périopératoire,

CHU Clermont-Ferrand, Clermont-Ferrand, France

B. Riu

Département d'anesthésie et de réanimation, CHU Purpan, Université Toulouse 3 Paul Sabatier, Toulouse, France

\section{K. Chaumoitre}

Service d'imagerie médicale, Hôpital Nord, Aix Marseille Université, Marseille, France

B. Allaouchiche

Département d'anesthésie et de réanimation, Hôpitaux Lyon-Sud, Hospices Civils de

Lyon et Université Lyon 1,

Lyon, France

D. De Backer

Department of intensive care, Erasme

hospital, Université libre de Bruxelles,

Brussels, Belgium

M. Leone

Centre d'Investigation Clinique 9502, Aix Marseille Université, Assistance Publique Hôpitaux de Marseille, Marseille, France

Abstract Objective: To describe current use and diagnostic and therapeutic impacts of point-of-care ultrasound (POCUS) in the intensive care unit (ICU).

Background: POCUS is of growing importance in the ICU. Several guidelines recommend its use for procedural guidance and diagnostic assessment. Nevertheless, its current use and clinical impact remain unknown. Methods: Prospective multicentric study in 142 ICUs in France, Belgium, and Switzerland. All the POCUS procedures performed during a 24-h period were prospectively analyzed. Data regarding patient condition and the POCUS procedures were collected. Factors associated with diagnostic and therapeutic impacts were identified.

Results: Among 1954 patients hospitalized during the study period, 1073 (55 \%) POCUS/day were performed in 709 (36\%) patients. POCUS served for diagnostic assessment in $932(87 \%)$ cases and procedural guidance in $141(13 \%)$ cases. Transthoracic echocardiography, lung ultrasound, and transcranial Doppler accounted for 51, 17, and $16 \%$ of procedures, respectively.

Diagnostic and therapeutic impacts of diagnostic POCUS examinations were 84 and $69 \%$, respectively. Ultrasound guidance was used in 54 and $15 \%$ of cases for central venous line and arterial catheter placement, respectively. Hemodynamic instability, emergency conditions, transthoracic echocardiography, and ultrasounds performed by certified intensivists themselves were independent factors affecting diagnostic or therapeutic impacts.

Conclusions: With regard to guidelines, POCUS utilization for procedural guidance remains insufficient. In contrast, POCUS for diagnostic assessment is of extensive use. Its impact on both diagnosis and treatment of ICU patients seems critical. This study identified factors associated with an improved clinical value of POCUS.

Keywords Ultrasound . Point-of-care - Diagnosis . Treatment · Echocardiography 


\section{Introduction}

Prompt diagnosis and early treatments are essential in intensive care unit (ICU) patients [1]. During the last few years, several guidelines have recommended using ultrasound for procedural guidance and diagnostic assessment [2-4]. Ultrasound can rapidly provide relevant information at the bedside [5].

As demonstrated in several monocentric studies, transthoracic echocardiography improves the performance of clinical cardiac examination [6-9]. Analogous results were obtained for pulmonary examination. Several studies showed that lung ultrasound performs better than chest radiograph $[10,11]$ and reduces the need for irradiative procedures [12]. In addition, the use of ultrasound was associated with up to $50 \%$ change of patient management [6-10].

Previous studies defined point-of-care ultrasound (POCUS) as ultrasonography brought to the patient and performed by the provider [13-16]. POCUS aims to avoid delays in diagnosis and treatment initiation [17]. However, in the ICU, the actual levels of POCUS implementation and contribution to patient management remain unknown. The primary aim of our study was to evaluate the prevalence of POCUS use in ICU patients. The secondary aims were to assess the diagnostic performance and therapeutic impact of POCUS in a large cohort of ICU patients. Finally, we assessed the factors that may influence the performance of POCUS.

\section{Materials and methods}

Study design

This 1-day, prospective, observational study was approved by the institutional review board (IRB) (Nîmes, France, 13/04-0208/27/2013) and the Commission Nationale de l'Informatique et des Libertés (DE20146005, 01/30/2014). The IRB waived the need for patient (or relative) consent. Local IRBs in other participating countries also approved the trial with waived consent.

Using several networks including AzuRea and CAR'Echo, we invited representatives of 160 ICUs to participate to the study. We recruited units from France, Switzerland, and Belgium. The representatives of $142(89 \%)$ ICUs accepted the invitation. The representatives of each unit prospectively collected all the ultrasound exams that were performed in their units during a 24 -h period starting on 11December 2014 at 8 a.m. There was no incentive to perform POCUS that day. Apart from the local coordinator, the other doctors participating in the trial were not aware of the goals of the trial. During the study, each operator performing an ultrasound examination filled in a case report form. Details on operator training, patient conditions, type of ultrasound, diagnosis, treatment changes, and timing of assessment were reported in the case report form. The day after the study, each investigator collected the total number of patients hospitalized and the total number of central venous line (CVC) or arterial line (A-line) placements. The case report forms are available in the Electronic Supplemental Material.

\section{Definitions}

The prevalence of POCUS was defined as the number of POCUS/number of patients hospitalized in the unit during the study period. The POCUS were classified into "procedural guidance" (ultrasound was used for an invasive procedure) or "diagnostic assessment" in the other cases [13]. We studied diagnostic and therapeutic impact as well as clinical value of POCUS in the "diagnostic assessment POCUS" group. "Procedural guidance POCUS" was excluded from this analysis. The "diagnostic impact" was defined as an ultrasound-induced confirmation or change in the current diagnosis according to the physician who performed the examination. The "therapeutic impact" was defined as an ultrasound-induced change in treatment and/or imaging ordering and/or patient triage according to the physician who performed the POCUS. These variables were determined during the study period. The "global clinical value" was defined as the combination of either the diagnostic impact or therapeutic impact [18]. An emergent ultrasound was defined as a POCUS performed in the first hour after the occurrence of the first clinical sign. We classified POCUS performed at ICU admission, during the hospitalization, during the day shift (from 8 a.m. to 6 p.m.), and during the night shift ( 6 p.m. to 8 a.m.). The operator classified the quality of images obtained for each procedure as good (full visualization of structures), average (partial visualization allowing assessment), or poor (no visualization or no possible assessment).

A trained physician was defined as a specialist skilled in a given procedure (cardiologists for echocardiography, radiologists for the other types of ultrasound evaluations). For intensivists, a certified physician was defined as an intensivist who received specific training in critical care echography, according to international guidelines [19]. Ultrasound guidance rates for $\mathrm{CVC}$ and A-line were defined as the ratio of the total number of CVC or A-line placements divided by the number of ultrasound-guided placements.

\section{Statistical analysis}

Statistical analysis was performed using R-Project 3.1 for GNU Linux Ubuntu (Vienna, Austria). For categorical 
variables, percentages were computed. Comparisons of percentages were performed with Fisher's exact test. We performed a multivariate analysis to assess the independent factors of therapeutic and diagnostic impact. Variables with a significance level at least 0.1 were included in the logistic regression model. The variables were selected by a step-by-step forward-backward model to minimize the Akaike's criterion. The statistical threshold for final significance was 0.05 .

Table 1 Features of intensive care units $(n=142)$ and patients $(n=709)$

\begin{tabular}{lc}
\hline Variables & $n$ \\
\hline Type of hospital (\%) & \\
University hospitals (\%) & $98(69)$ \\
General hospitals (\%) & $44(31)$ \\
Type of ICU (\%) & $95(70)$ \\
Polyvalent & $17(13)$ \\
Medical & $22(17)$ \\
Pediatric & \\
Patients & $603(85)$ \\
Adult patients (\%) & $106(15)$ \\
Patients younger than 15 years (\%) & $393(43)$ \\
Shock (\%) & $588(64)$ \\
Mechanical ventilation (\%) & $45(32-58)$ \\
SAPS 2 median (IQR) & \\
Timing of POCUS & $402(44)$ \\
Emergent (<1 h after the first clinical sign) $(\%)$ & $183(20)$ \\
At ICU admission (\%) & $222(25)$ \\
During night shift (\%) & \\
POCUS and procedures & $65(47)$ \\
Disinfection protocol (\%) & $29(20)$ \\
Management algorithm (\%) & \\
Skill level of operator & $821(89)$ \\
Performed by an intensivist (\%) & $752(81)$ \\
Board-certified operator $(\%)$ & \\
\hline
\end{tabular}

$I C U$ intensive care unit, SAPS simplified acute physiology score 2, $I Q R$ interquartile range, $P O C U S$ point-of-care ultrasound

\section{Results}

During the study day, 1073 (55\%) POCUS were performed in 709 (36\%) out of 1954 patients hospitalized in the 142 ICUs. The quality of images was classified as good, average, and poor for 794 (74 \%), 236 (22\%), and $43(4 \%)$ POCUS, respectively. Features of patients and units are sumarized in Table 1.

The use of POCUS was aimed at assessing diagnosis in $932(87 \%)$ cases and procedural guidance in $141(13 \%)$ cases (Fig. 1). The diagnostic and therapeutic impacts were 84 and $69 \%$, respectively (Fig. 2). The clinical value combining either the diagnostic impact or the therapeutic impact was assessed at $85 \%$. With respect to diagnostic impact, the use of POCUS confirmed or changed the diagnosis in 63 and $21 \%$ of cases, respectively. Heart, lung, brain, and miscellaneous other sites represented 51, 17, 16, and $16 \%$ of POCUS, respectively (Fig. 2). Performing POCUS resulted in the initiation of 373 therapeutic interventions, the decision to stop interventions in 73 cases, or not to perform additional examinations in 108 cases (Fig. 1); (Table 2). Hemodynamic interventions including fluid bolus $(n=115)$, fluid depletion $(n=80)$, and catecholamine administration $(n=43)$ were the most prominent POCUS-driven interventions. With respect to 183 central venous line placements and 127 arterial catheter placements, POCUS was used in $99(54 \%)$ cases and 15 (13\%) cases, respectively.

The factors associated with diagnostic and therapeutic impacts in the univariate analysis are shown in Table 3. In the multivariate analysis, being a certified operator, managing a shocked patient, having a disinfection protocol, and using an algorithm of management were associated with significant changes in the diagnostic impact (Table 3). Being an intensivist, having a daily practice, assessing a child, processing in emergency,
Fig. 1 Flowchart showing prevalence and diagnostic and therapeutic impacts of point-ofcare ultrasounds

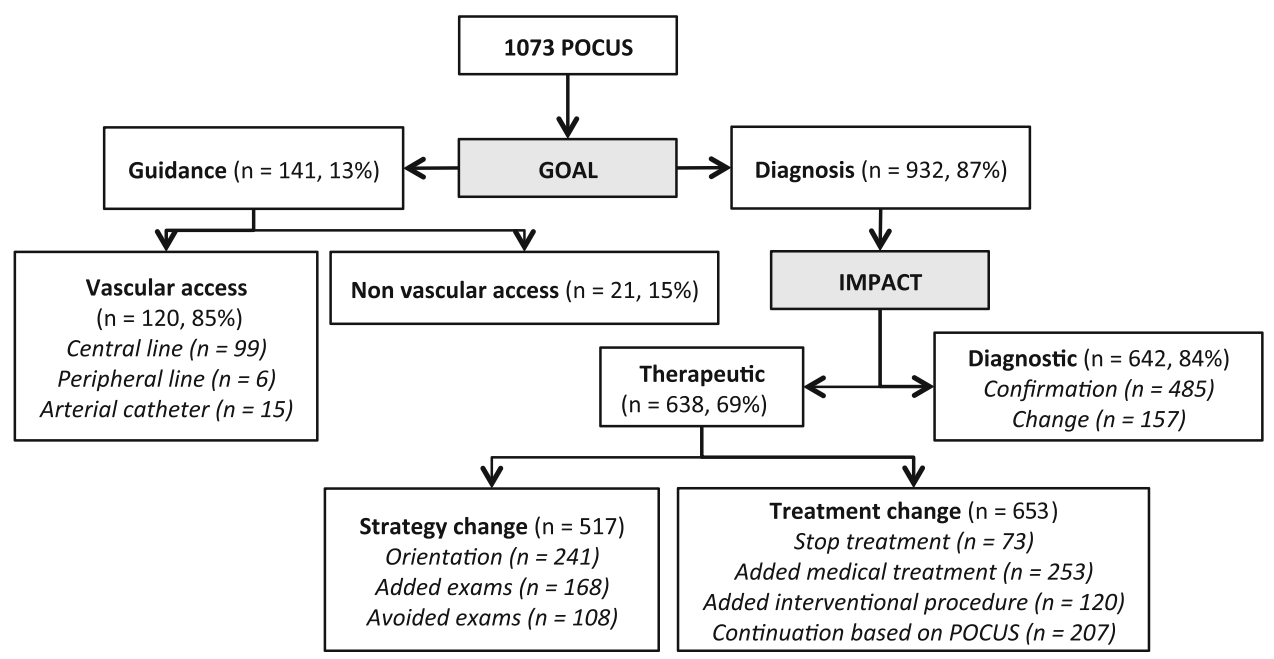


Fig. 2 Rates of point-of-care ultrasound use depending on site

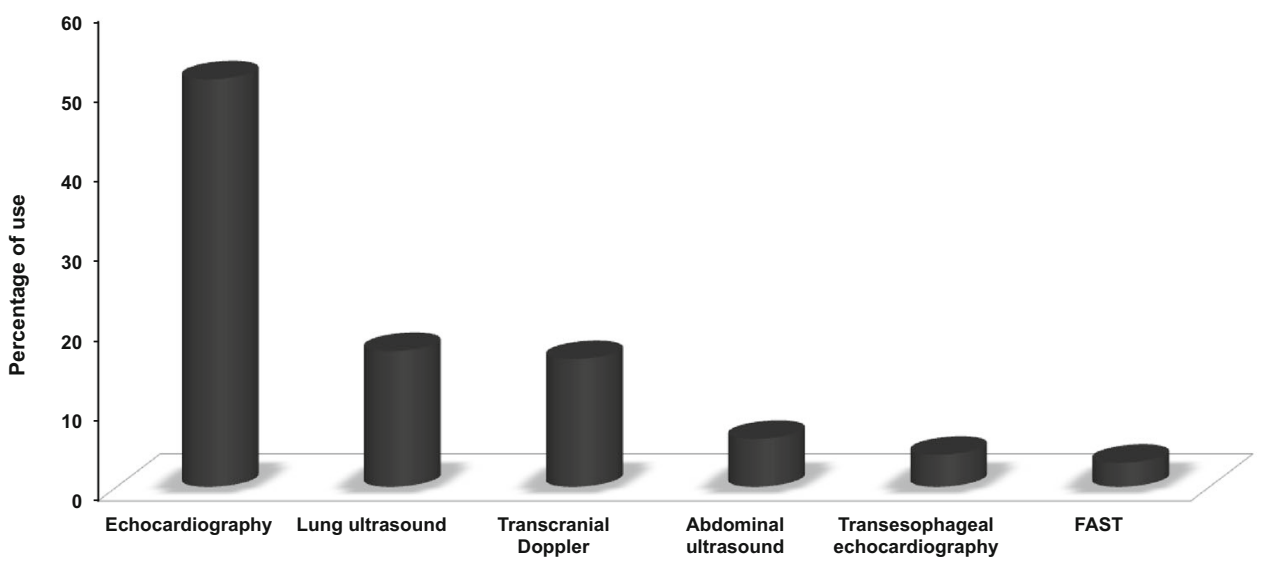

Table 2 Interventions associated with point-of-care ultrasound performance

\begin{tabular}{lc}
\hline Intervention & $n=373(\%)$ \\
\hline Hemodynamics & \\
Fluid bolus & $115(31)$ \\
Fluid depletion & $80(21)$ \\
Catecholamines & $43(12)$ \\
Pulmonary artery hypertension treatment & $11(2.9)$ \\
Invasive procedures & \\
Surgery/interventional radiology & $13(3.4)$ \\
Chest tube insertion & $48(13)$ \\
Medical treatments & \\
Antibiotics & $10(2.6)$ \\
Sedation & $6(1.6)$ \\
Mechanical ventilation setting & $9(2.4)$ \\
Anticoagulation & $7(1.8)$ \\
Others (miscellaneous) & $31(8.3)$ \\
\hline
\end{tabular}

working in a university hospital, and transthoracic echocardiography were independent variables associated with therapeutic impact (Table 3).

\section{Discussion}

In this large 1-day observational trial we observed that at least one POCUS is performed in one-third of the patients hospitalized in the ICU that day and that it impacted patient management in $85 \%$ of cases.

POCUS was used in $36 \%$ of our patients/day. Even though ICU guidelines recommend a large use of POCUS $[2,4,19]$, the prevalence of POCUS use has been poorly described. Only a few monocentric studies assessed the performance of POCUS in ICUs $[6,7,9,10,20]$. A previous French survey showed that in the majority of ICUs echocardiography was used about once a day [21]. Interestingly, intensivists performed POCUS in $90 \%$ of cases. This finding confirms the good diffusion of this technique among intensivists. In addition, more than $80 \%$ of operators were board-certified and used ultrasound on a daily basis.

A diagnostic impact was reported in $84 \%$ of cases. The use of POCUS changed the diagnosis in $21 \%$ of cases, while a suspected diagnosis was confirmed in $63 \%$ of cases. This striking result highlights the emergence of POCUS as a diagnostic tool at the bedside. We did not collect the specific diagnosis. However, as transthoracic echocardiography represented more than $50 \%$ of POCUS, our study underlines that ultrasounds play a key role for the hemodynamic management of ICU patients.

In $69 \%$ of cases, the use of POCUS was associated with interventions including treatment, imagery ordering, and patient triage. In line with the diagnostic impact, most interventions were related to hemodynamics, underlining once again the key role of transthoracic echocardiography. Fluid loading, fluid depletion, and vasopressor administration were among the most frequent interventions. Several studies showed that hemodynamic-related interventions based on echocardiography are efficient [22-25]. Elsewhere, Aliaga et al. reported $54 \%$ of therapeutic changes after chest computed tomography [26]. However, the type of expectations probably differs between POCUS and computed tomography scan.

In our study, cardiac examination was the most common indication for POCUS. Transthoracic echocardiograhy has been associated with improvement of diagnosis in patients with acute respiratory failure and/or shock $[6-8,27]$ and is now recommended in guidelines [28]. In our cohort, lung ultrasound was the second most common type of POCUS used. The steep learning curve favors the use of this procedure, which provides interesting information about pleura, parenchyma, and lung aeration state in critical situations [10, 29-31]. Lung ultrasound was associated with reduced requirements for chest radiographs and computed tomography. This shift was associated with a decreased amount of irradiation and medical cost [12, 32]. In recent studies, a global approach combining heart and lung 
Table 3 Factors associated with diagnostic and therapeutic impacts

\begin{tabular}{|c|c|c|c|c|c|}
\hline \multirow[t]{2}{*}{ Variable } & \multicolumn{3}{|c|}{ Univariate analysis } & \multicolumn{2}{|c|}{ Multivariate analysis } \\
\hline & Yes $n(\%)$ & No $n(\%)$ & $p$ & OR $(95 \% \mathrm{CI})$ & $p$ \\
\hline \multicolumn{6}{|l|}{ Diagnostic impact } \\
\hline US certified & $464(86)$ & $178(78)$ & 0.005 & $2.0(1.2-3.1)$ & 0.002 \\
\hline Disinfection protocol & $311(90)$ & $312(80)$ & $<0.001$ & $2.4(1.5-3.7)$ & 0.004 \\
\hline Shock & $293(88)$ & $337(80)$ & 0.05 & $1.5(1.0-2.4)$ & 0.01 \\
\hline Management algorithm & $136(75)$ & $487(87)$ & $<0.001$ & $0.4(0.3-0.7)$ & $<0.001$ \\
\hline Pediatric patient & $66(71)$ & $560(86)$ & $<0.001$ & & \\
\hline Adult patient & $560(86)$ & $66(71)$ & $<0.001$ & & \\
\hline Emergency US & $312(87)$ & $318(80)$ & 0.02 & & \\
\hline $\mathrm{PaO}_{2} / \mathrm{FiO}_{2}<300 \mathrm{mmHg}$ & $268(86)$ & $354(82)$ & 0.1 & & \\
\hline \multicolumn{6}{|l|}{ Therapeutic impact } \\
\hline Operator: intensivist & $579(71)$ & $55(55)$ & 0.04 & $1.7(1.0-2.9)$ & 0.002 \\
\hline Daily practice of US & $509(71)$ & $124(61)$ & 0.001 & $1.8(1.2-2.7)$ & 0.01 \\
\hline TTE & $349(75)$ & $284(63)$ & 0.001 & $1.7(1.2-2.3)$ & $<0.001$ \\
\hline Emergency US & $319(79)$ & $312(61)$ & $<0.001$ & $2.6(1.9-3.8)$ & $<0.001$ \\
\hline University hospital & $430(65)$ & $180(79)$ & 0.01 & $0.6(0.4-0.9)$ & $<0.001$ \\
\hline Pediatric patient & $70(52)$ & $550(72)$ & $<0.001$ & $0.4(0.3-0.7)$ & $<0.001$ \\
\hline US certified & $528(71)$ & $110(62)$ & $<0.001$ & & \\
\hline Ward US & $166(75)$ & $457(67)$ & 0.03 & & \\
\hline Shock & $287(73)$ & $342(66)$ & 0.03 & & \\
\hline
\end{tabular}

OR odds ratio, $C I$ confidence interval, US ultrasound, TTE transthoracic echocardiography

assessment improved diagnostic performance [27, 33]. Thus, one may expect a larger use of this promising technique. The gap between echocardiography and lung ultrasound probably reflects the differences in the penetration rate of the two techniques. Recent guidelines should reduce this gap [2, 34]. In our study, transcranial Doppler was the third most common type of POCUS used. Transcranial Doppler aimed to monitor cerebral hemodynamics, as an alternative or complement to intracranial pressure monitoring [22, 23].

POCUS was used to guide procedures in less than $15 \%$ of indications. Only half of CVC insertions were ultrasound-guided, despite a strong level of evidence and recommendations for using ultrasound guidance during CVC placement [4]. This result is surprising since an ultrasound device was available in all the units. Ultrasound was used in $15 \%$ for the placement of A lines. This procedure is supported by guidelines with a strong level of evidence [35]. Therefore our results show that, in the study group of ICUs, compliance with this recommendation can be improved.

Finally, we identified independent factors associated with the diagnostic and therapeutic impacts. Operator experience (trained or certified physician), disinfection protocol, and presence of shock were associated with increased diagnostic impact. The disinfection protocol may be an indirect marker of appropriate use of POCUS and quality of care. The operator's experience probably reflects a certain level of expertise. With respect to shock management, several studies reported the performance of ultrasound in those patients $[21,26]$. In terms of diagnostic impact, having pre-established therapeutic algorithms was associated with reduced performance. In our opinion, this result reflects the challenge to show the relevance of algorithms in ICU patients [36, 37]. With respect to therapeutic impact, our results showed that being an intensivist, having a routine use of POCUS, and performing an emergency POCUS were associated with an increased impact. Those findings suggest that at the bedside POCUS facilitates the intensivist's decisionmaking process. This also encourages the development of specific training for intensivists [38]. Unsurprisingly, transthoracic echocardiography also has a stronger therapeutic impact than other procedures. Hemodynamic assessment represented more than half of the interventions, probably explaining these associations.

Our study has several limitations. Although this was not requested, only units with an available ultrasound device participated. This represents probably an intrinsic bias of recruitment. In addition, we conducted the study in Belgium, Switzerland, and France. As we cannot determinate the rate of uptake of POCUS in other countries, it is difficult to determine how our findings are able to be extrapolated elsewhere. As the study was open, the investigators were aware of the study day. Therefore, they may have been encouraged to use the POCUS during the study day. However, this deviation should result in decreased rates of diagnostic and therapeutic impacts, which are high in our study. Moreover, the impact of ultrasound on the medical decision was also determined by the operator. In relation to our aims, the loss of data would have been a bias exceeding that of the non-blinded assessment. In terms of diagnosis 
and treatment, POCUS was not compared with a standard of care. Nevertheless, this process was confirmed in several previous studies $[6,7,10,11]$. Finally, our study was not aimed at assessing the appropriateness of interventions and the patient outcomes. Our goal was to determine the use of POCUS in real life.

Our study clearly shows the high prevalence of POCUS use in ICUs. Moreover, we showed that POCUS is not an observational game but strongly impacts the management of the most critically ill patients. Intensivists acquired adequate skills for using ultrasound at the bedside. Future efforts should stress the placement of intravascular lines using ultrasound.

Acknowledgments Author contributions: Drs Zieleskiewicz and Leone had full access to all of the data in the study and take responsibility for the integrity of the data and the accuracy of the data analysis.
Study concept and design: Arbelot, Chaumoitre, Cholley, Constantin, Jaber, Lakhal, Leone, Martin, Perbet, Zieleskiewicz.

Acquisition, analysis or interpretation of data: Arbelot, Bouhemad, Demory, M. Muller, L. Muller, Cholley, Duperret, Hammad, Langeron, Mahjoub, Maury, Meaudre, Michel, Nafati, Quintard, Bertrand, Guervilly, Jaber, Riu, Perbet.

Drafting of the manuscript: Lakhal, Meresse, De Backer, Leone, Allaouchiche, Zieleskiewicz, L Muller, Ichai, Lefrant.

Statistical analysis: Antonini, Leone, Meresse, Vigne, Zieleskiewicz.

Study supervision: Martin, Leone, De Backer, Chaumoitre.

\section{Members of the CAR'Echo and AzuRea Collaborative Networks}

Table 4 presents a list of members of the CAR'Echo and AzuRea Collaborative Networks.

Table 4 List of investigators

\begin{tabular}{|c|c|}
\hline FISCHER Marc-Olivier & Pôle Réanimations Anesthésie SAMU/SMUR, CHU de Caen, Caen \\
\hline RINAUDO Marc & Réanimation chirurgicale, CHLS, Lyon \\
\hline $\begin{array}{l}\text { HUGON-VALLET } \\
\text { Elisabeth }\end{array}$ & Réanimation médicale, CHLS, Lyon \\
\hline MARCOTTE Guillaume & $\begin{array}{l}\text { Hospices Civils de Lyon, Département d'Anesthésie et Réanimation Chirurgicale, Groupement Hospitalier } \\
\text { Edouard Herriot, Lyon }\end{array}$ \\
\hline LALLEMANT Florence & Service des urgences chirurgicales et dechocage, Hôpital Roger Salengro, Chru Lille, Lille \\
\hline DESSERTAINE Géraldine & Réanimation CVT-CHU Grenoble, Grenoble \\
\hline BRISSAUD Olivier & Unité de réanimation néonatale et pédiatrique, Bordeaux \\
\hline NOVY Emmanuel & Service de Réanimation médicale, CHU de Nancy, Hôpitaux de Brabois, Vandoeuvre les Nancy \\
\hline ROBINE Adrien & Service de réanimation polyvalente, $\mathrm{CH}$ de Bourg en Bresse, Bourg en Bresse \\
\hline GIACARDI Christophe & $\begin{array}{l}\text { Department of Anesthesiology and Critical Care Medicine, Military Teaching Hospital Clermont Tonnerre, } \\
\text { Brest }\end{array}$ \\
\hline BOUZAT Pierre & $\begin{array}{l}\text { Department of anesthesiology and intensive care, Michallon hospital Grenoble University Hospital, } \\
\text { Grenoble }\end{array}$ \\
\hline DELMAS Clement & Réanimation polyvalente, CHU Toulouse Rangueil, Toulouse \\
\hline KAMEL Toufik & Réanimation médicale polyvalente, centre hospitalier régional d'Orléans, Orléans \\
\hline VIVIER Emmanuel & Reanimation Polyvalente, Centre hospitalier Saint Joseph Saint Luc, Lyon \\
\hline BRENAS François & Service de reanimation, CH Le Puy en Velay, Le Puy en Velay \\
\hline MACHROUB Zakia & Réanimation, Groupe Hospitalier du Sud de l'Oise, Creil \\
\hline AMOUR Julien & $\begin{array}{l}\text { Unité Anesthésie et de Réanimation de Chirurgie Cardiaque de l'Institut de Cardiologie, Hôpital Pitié- } \\
\text { Salpêtrière, Paris }\end{array}$ \\
\hline BERGOUNIOUX Jean & Pediatric Intensive Care, Raymond Poincaré Hospital, APHP, Garches \\
\hline DE LA VEGA Christophe & Réanimation, centre hospitalier, Carcassonne \\
\hline JURADO Andres & CH Draguignan, Draguignan \\
\hline BARTHELEMY Romain & Réanimation chirurgicale polyvalente, Hôpital Lariboisière, Paris \\
\hline BUSSIENNE Frédéric & Service de Réanimation polyvalente, CHÚ La Réunion, Saint Denis \\
\hline MIREK Sébastien & CHU Bocage Central, Service d'Anesthésie-Réanimation, Dijon \\
\hline YOUSSEF Nadya & $\begin{array}{l}\text { Réanimation Pédiatrique et Néonatale, CHU Bicêtre-Hôpitaux Universitaires Paris-Sud AP-HP, Kremlin } \\
\text { Bicêtre }\end{array}$ \\
\hline BLANC Thierry & Pédiatrie neonatale et reanimation, hopital Charles Nicolle, Rouen \\
\hline LEGER Pierre-Louis & Service de réanimation néonatale et pédiatrique, Paris \\
\hline BERTRAND Pierre-Marie & Cannes Hospital, Intensive Care Unit, Cannes \\
\hline GAYAT Etienne & $\begin{array}{l}\text { Département d'Anesthésie-Réanimation-SMUR, Hôpitaux Universitaires Saint Louis-Lariboisière- } \\
\text { Fernand Widal, Paris }\end{array}$ \\
\hline BRISSON Hélène & $\begin{array}{l}\text { Réanimation Chirurgicale Polyvalente, Département d'Anesthésie-Réanimation, Hôpital Universitaire } \\
\text { Pitié-Salpêtrière, Paris }\end{array}$ \\
\hline FINGE Toufic & Service de Réanimation, Hôpital Privé Les Franciscaines, NIMES \\
\hline RIGAUD Jean Claude & Inimation Polyvalente, Hopital Privé La Casamance, Aubagne \\
\hline
\end{tabular}


Table 4 continued

\begin{tabular}{|c|c|}
\hline PICARD Julien & Réanimation Polyvalente Chirurgicale, Grenoble \\
\hline BRUN Jean Paul & IPC, Marseille \\
\hline CONTARGYRIS Claire & HIA Laveran, Marseille \\
\hline PRAT Dominique & Service de Réanimation Polyvalente, Hôpital Antoine Béclère, Clamart \\
\hline LAPLACE Christian & Réanimation Chirurgicale, Hôpitaux Universitaires Paris-Sud, Hôpital Bicêtre, Le Kremlin Bicêtre \\
\hline MARCOUX M.O. & Unité de réanimation mixte et polyvalente, Hôpital des enfants, Toulouse \\
\hline CRONIER Pierrick & Service de réanimation polyvalente, Centre Hospitalier Sud-Francilien, Corbeil-Essonnes \\
\hline ZENDER Hervé & $\begin{array}{l}\text { Hopital neuchâtelois, Service de médecine interne, Service des soins intensifs, Département de médecine, } \\
\text { La Chaux-de-Fonds, Suisse }\end{array}$ \\
\hline BELLEC Frédéric & Service de réanimation polyvalente, Montauban \\
\hline LIGI Isabelle & Département de néonatologie et réanimation néonatale, Hôpital La Conception, Marseille \\
\hline FUMEAUX Thierry & Service de Médecine et des Soins Intensifs, GHOL-Hôpital de Nyon, Nyon, Suisse \\
\hline DANIN Pierre-Eric & Réanimation médico-chirurgicale l'Archet 2, CHU de Nice \\
\hline ELAROUSSI Djilali & Service d'anesthésie et de réanumation 1, hopital Bretonneau, CHU Tours \\
\hline COMANDINI Michel & Service de réanimation polyvalente, Hôpital Manchester, Charleville-Mezieres \\
\hline PAPAZIAN Laurent & Hôpital Nord Réanimation des Détresses Respiratoires et des Infections Sévères, Marseille \\
\hline PEIGNE Vincent & Service de reanimation, HIA Percy, Clamart \\
\hline ESSID Aben & Unité de soins continu, réanimation pédiatrique, Hôpital Raymond Poincar \\
\hline DUSANG Benjamin & Réanimation pédiatrique et Unité de Surveillance continue pédiatrique, CHU de la Réunion, Saint Pierre \\
\hline GUINET Patrick & Chirurgie Thoracique et Cardio-Vasculaire CHU Pontchaillou, Rennes \\
\hline GREGOIRE Vincent & Réanimation Polyvalente, Hôpital de Fréjus Saint Raphael, Fréjus \\
\hline ARGAUD Laurent & Réanimation Médicale, Hôpital Edouard Herriot, Hospices Civils de Lyon, Lyon \\
\hline PHAM Tài & AP-HP, Hôpital Tenon, Unité de Réanimation médico-chirurgicale, Hôpital Tenon, Paris \\
\hline SAVY Nadia & Réanimation Pédiatrique et Néonatale, CHU Estaing, Clermont Ferrand \\
\hline VINCLAIR Marc & NeuroAnesthésieRéanimation, Pôle Anesthésie Réanimation, CHU de Grenoble, Grenoble \\
\hline BEGOT Emmanuelle & Service de Réanimation Polyvalente, Chu de Limoges, Limoges \\
\hline BAUDEL Jean-Luc & Service de réanimation médicale, Hôpital Saint Antoine, Paris \\
\hline BOULET Eric & Réanimation Médico-Chirurgicale, Hôpital René Dubos, Pontoise \\
\hline $\begin{array}{l}\text { ZOGHEIB Elie } \\
\text { GUILBART Ma }\end{array}$ & Réanimation cardio thoracique et vasculaire, Pôle anesthésie réanimation, CHU Amiens Picardie, Amiens \\
\hline BOTTE Astrid & $\begin{array}{l}\text { Réanimation et Unité de Surveillance Continue pédiatriques, Hôpital Jeanne de Flandre, CHU de Lille, } \\
\text { Lille }\end{array}$ \\
\hline PRAT Gwénaël & Réanimation médicale, CHU Cavale Blanche, Brest \\
\hline CRISTINAR Mircea & Réanimation Chirurgicale Cardiovasculaire, Nouvel Hopital Civil, Strasbourg \\
\hline ALMAYRAC Agnès & SSPI-Accueil des Polytraumatisés, Hôpital Universitaire Pitié Salpêtrière, Paris \\
\hline TAGAN Damien & Service des soins intensifs, Hôpital Riviera-Chablais, Vevey \\
\hline STEINBACH Marie Isabelle & Centre Hospitalier Intercommunal Castres-Mazamet, Castres \\
\hline $\begin{array}{l}\text { KETTERER-MARTINON } \\
\text { Sophie }\end{array}$ & $\begin{array}{l}\text { Service de Réanimation et Soins continus pédiatriques, Maison de la Femme de la Mère et de l'Enfant, } \\
\text { CHU de Martinique, Fort de France }\end{array}$ \\
\hline SOUSSI Sabri & $\begin{array}{l}\text { Centre de Traitement des Brûlés, Département d'Anesthésie-réanimation, AP-HP Groupe Hospitalier } \\
\text { Saint-Louis Lariboisière Fernand-Widal, Université Paris Denis Diderot, Paris }\end{array}$ \\
\hline BOUSSICAULT Gérald & Service de Réanimation Pédiatrique, CHU Angers, Angers \\
\hline FABRE Xavier & Réanimation polyvalente, CHR de Roanne, Roanne \\
\hline AFANETTI Mickael & $\begin{array}{l}\text { Réanimation et Soins Continus Pédiatriques, Centre de Réference des Morts Innatendues du Nourrisson, } \\
\text { Hôpitaux Pédiatriques de Nice CHU-Lenval, Nice }\end{array}$ \\
\hline COLOMB Benoît & Réanimation Pédiatrique, Dijon \\
\hline BERINGUE Frédérique & Médecine et réanimation néonatale, Pole Femme mère Enfant, CHU Hotel Dieu, Angers \\
\hline MOURISSOUX Gaëlle & Service de réanimation médicale, Hôpital Saint-André CHU de Bordeaux, Bordeaux \\
\hline DOYEN Denis & Réanimation Médicale, L’Archet 1-CHU de Nice, Nice \\
\hline GAILLOT Théophile & Service de réanimation pédiatrique, Hôpital sud, Rennes \\
\hline REMERAND Francis & Service anesthésie réanimation 2, Hôpital Trousseau, CHRU de Tours, Tours \\
\hline SIMON Georges & Réanimation polyvalente, Troyes \\
\hline MASSERET Elodie & Service de Réanimation Chirurgicale, Hôpital Pontchaillou CHU Rennes, Rennes \\
\hline $\begin{array}{l}\text { MORICHAU- } \\
\text { BEAUCHANT Tristan }\end{array}$ & Service de Réanimation Polyvalente, Hôpital Cochin, Hôpitaux Paris Centre, AP-HP, Paris \\
\hline PRADEL Gaël & Service de réanimation polyvalente, Centre Hospitalier d'Avignon, Avignon \\
\hline PICARD Walter & Service de réanimation Pau, CH Pau, Pau \\
\hline KERFORNE Thomas & Service d'Anesthésie-Réanimation du CHU de Poitiers, Poitiers \\
\hline GARENNE Armelle & Réanimation néonatale et pédiatrique, CHRU Brest, Brest \\
\hline VOISIN Benoit & Réanimation Polyvalente, Centre Hospitalier Béthune Beuvry, Béthune \\
\hline FRANCES-MOUSSI Julie & Unité de Soins Intensifs Néphrologiques, Hopital de la conception, Marseille \\
\hline GOMERT Romain & URCC, Hôpital de la Timone Adulte, Marseille, France \\
\hline
\end{tabular}


Table 4 continued

\begin{tabular}{ll}
\hline $\begin{array}{l}\text { MAURICE-SZAMBURSKI } \\
\text { Axel } \\
\text { BRUDER Nicolas }\end{array}$ & Réanimation Polyvalente, Hôpital de la Timone Adulte, Marseille, France \\
$\begin{array}{l}\text { WIRAMUS Sandrine } \\
\text { ALBANESE Jacques }\end{array}$ & Réanimation des Brulés, Hôpital de la Conception, Marseille, France \\
$\begin{array}{l}\text { GROSSMITH Gaston } \\
\text { XERIDAT François }\end{array}$ & $\begin{array}{l}\text { Réanimation polyvalente, Hôpital d'Aubagne, Aubagne } \\
\text { CASTANIER Mathias }\end{array}$ \\
\hline
\end{tabular}

\section{References}

1. Dellinger RP, Levy MM, Rhodes A, Annane D, Gerlach H, Opal SM, Sevransky JE, Sprung CL, Douglas IS, Jaeschke R, Osborn TM, Nunnally ME, Townsend SR, Reinhart K, Kleinpell RM, Angus DC, Deutschman CS, Machado FR, Rubenfeld GD, Webb S, Beale RJ, Vincent JL, Moreno R, Surviving Sepsis Campaign Guidelines Committee including The Pediatric Subgroup (2013) Surviving Sepsis Campaign: international guidelines for management of severe sepsis and septic shock, 2012. Intensive Care Med 39:165-228

2. Volpicelli G, Elbarbary M, Blaivas M, Lichtenstein DA, Mathis G, Kirkpatrick AW, Melniker L, Gargani L, Noble VE, Via G, Dean A, Tsung JW, Soldati G, Copetti R, Bouhemad B, Reissig A, Agricola E, Rouby JJ, Arbelot C, Liteplo A, Sargsyan A, Silva F, Hoppmann R, Breitkreutz R, Seibel A, Neri L, Storti E, Petrovic T (2012) International Liaison Committee on Lung Ultrasound (ILC-LUS) for International Consensus Conference on Lung Ultrasound (ICC-LUS). Intensive Care Med 38:577-591

3. Bouzat P, Francony G, Declety P, Genty C, Kaddour A, Bessou P, Brun J, Jacquot C, Chabardes S, Bosson JL, Payen JF (2011) Transcranial Doppler to screen on admission patients with mild to moderate traumatic brain injury. Neurosurgery 68:1603-1610

4. Troianos CA, Hartman GS, Glas KE, Skubas NJ, Eberhardt RT, Walker JD, Reeves ST; Councils on Intraoperative Echocardiography and Vascular Ultrasound of the American Society of Echocardiography (2011) Guidelines for performing ultrasound guided vascular cannulation: recommendations of the American Society of

Echocardiography and the Society of Cardiovascular Anesthesiologists. J Am Soc Echocardiogr 24:1291-1318
5. Laursen CB, Sloth E, Lambrechtsen J, Lassen AT, Madsen PH, Henriksen DP, Davidsen JR, Rasmussen F (2013)

Focused sonography of the heart, lungs, and deep veins identifies missed lifethreatening conditions in admitted patients with acute respiratory symptoms. Chest 144:1868-1875

6. Joseph MX, Disney PJS, Da Costa R, Hutchison SJ (2004) Transthoracic echocardiography to identify or exclude cardiac cause of shock. Chest 126:1592-1597

7. Orme RML, Oram MP, McKinstry CE (2009) Impact of echocardiography on patient management in the intensive care unit: an audit of district general hospital practice. Br J Anaesth 102:340-344

8. Bossone E, DiGiovine B, Watts S, Marcovitz PA, Carey L, Watts C, Armstrong WF (2002) Range and prevalence of cardiac abnormalities in patients hospitalized in a medical ICU. Chest 122:1370-1376

9. Manno E, Navarra M, Faccio L, Motevallian M, Bertolaccini L, Mfochivè A, Pesce M, Evangelista A (2012) Deep impact of ultrasound in the intensive care unit: the "ICU-sound" protocol. Anesthesiology 117:801-809

10. Lichtenstein D, Goldstein I, Mourgeon E, Cluzel P, Grenier P, Rouby JJ (2004) Comparative diagnostic performances of auscultation, chest radiography, and lung ultrasonography in acute respiratory distress syndrome. Anesthesiology 100:9-15

11. Xirouchaki N, Magkanas E, Vaporidi K, Kondili E, Plataki M, Patrianakos A, Akoumianaki E, Georgopoulos D (2011) Lung ultrasound in critically ill patients: comparison with bedside chest radiography. Intensive Care Med $37: 1488-1493$
12. Peris A, Tutino L, Zagli G, Batacchi $S$, Cianchi G, Spina R, Bonizzoli M, Migliaccio L, Perretta L, Bartolini M, Ban K, Balik M (2010) The use of point-of-care bedside lung ultrasound significantly reduces the number of radiographs and computed tomography scans in critically ill patients. Anesth Analg 111:687-692

13. Moore CL, Copel JA (2011) Point-ofcare ultrasonography. N Engl J Med 364:749-757

14. Vignon P, Dugard A, Abraham J, Belcour D, Gondran G, Pepino F, Marin B, François B, Gastinne H (2007) Focused training for goal-oriented hand-held echocardiography performed by noncardiologist residents in the intensive care unit. Intensive Care Med 33:1795-1799

15. Chalumeau-Lemoine L, Baudel JL, Das V, Arrivé L, Noblinski B, Guidet B, Offenstadt G, Maury E (2009) Results of short-term training of naïve physicians in focused general ultrasonography in an intensive-care unit. Intensive Care Med 35:1767-1771

16. Carrié C, Biais M, Lafitte S, Grenier N Revel P, Janvier G (2014) Goal-directed ultrasound in emergency medicine: evaluation of a specific training program using an ultrasonic stethoscope. Eur J Emerg Med. doi: 10.1097/MEJ.0000000000000172

17. Oks M, Cleven KL, Cardenas-Garcia J, Schaub JA, Koenig S, Cohen RI, Mayo PH, Narasimhan M (2014) The effect of point-of-care ultrasonography on imaging studies in the medical ICU: a comparative study. Chest 146:1574-1577

18. Lakhal K, Serveaux-Delous M, Lefrant JY, Capdevila X, Jaber S, AzuRéa network for the RadioDay study group (2012) Chest radiographs in 104 French ICUs: current prescription strategies and clinical value (the RadioDay study). Intensive Care Med 38:1787-1799 
19. Mayo PH, Beaulieu Y, Doelken P, Feller-Kopman D, Harrod C, Kaplan A, Oropello J, Vieillard-Baron A, Axler O, Lichtenstein D, Maury E, Slama M, Vignon P (2009) American College of Chest Physicians/La Société de Réanimation de Langue Française statement on competence in critical care ultrasonography. Chest 135:1050-1060

20. Volpicelli G, Lamorte A, Tullio M, Cardinale L, Giraudo M, Stefanone V, Boero E, Nazerian P, Pozzi R, Frascisco MF (2013) Point-of-care multiorgan ultrasonography for the evaluation of undifferentiated hypotension in the emergency department. Intensive Care Med 39:1290-1298

21. Quintard H, Philip I, Ichai C (2011) French survey on current use of ultrasound in the critical care unit: ECHOREA. Ann Fr Anesth Reanim 30:e69-73

22. Feissel M, Michard F, Faller JP, Teboul JL (2004) The respiratory variation in inferior vena cava diameter as a guide to fluid therapy. Intensive Care Med 30:1834-1837

23. Muller L, Toumi M, Bousquet PJ, RiuPoulenc B, Louart G, Candela D, Zoric L, Suehs C, de La Coussaye JE, Molinari N, Lefrant JY; AzuRéa Group (2011) An increase in aortic blood flow after an infusion of $100 \mathrm{ml}$ colloid over 1 minute can predict fluid responsiveness: the mini-fluid challenge study. Anesthesiology 115:541-547

24. Lamia B, Ochagavia A, Monnet X, Chemla D, Richard C, Teboul JL (2007) Echocardiographic prediction of volume responsiveness in critically ill patients with spontaneously breathing activity. Intensive Care Med 33:1125-1132

25. Brun C, Zieleskiewicz L, Textoris J, Muller L, Bellefleur JP, Antonini F, Tourret M, Ortega D, Vellin A, Lefrant JY, Boubli L, Bretelle F, Martin C, Leone M (2013) Prediction of fluid responsiveness in severe preeclamptic patients with oliguria. Intensive Care Med 39:593-600
26. Aliaga M, Forel JM, De Bourmont $\mathrm{S}$, Jung B, Thomas G, Mahul M, Bisbal M, Nougaret S, Hraiech S, Roch A, Chaumoitre K, Jaber S, Gainnier M, Papazian L (2015) Diagnostic yield and safety of CT scans in ICU. Intensive Care Med 41:436-443

27. Bataille B, Riu B, Ferre F, Moussot PE, Mari A, Brunel E, Ruiz J, Mora M, Fourcade O, Genestal M, Silva S (2014) Integrated use of bedside lung ultrasound and echocardiography in acute respiratory failure: a prospective observational study in ICU. Chest 146:1586-1593

28. Cecconi M, De Backer D, Antonelli M, Beale R, Bakker J, Hofer C, Jaeschke R, Mebazaa A, Pinsky MR, Teboul JL, Vincent JL, Rhodes A (2014) Consensus on circulatory shock and hemodynamic monitoring. Task force of the European Society of Intensive Care Medicine. Intensive Care Med 40:1795-1815

29. Bouhemad B, Brisson H, Le-Guen M, Arbelot C, Lu Q, Rouby JJ (2011) Bedside ultrasound assessment of positive end-expiratory pressureinduced lung recruitment. Am J Respir Crit Care Med 183:341-347

30. Bouhemad B, Liu ZH, Arbelot C, Zhang M, Ferarri F, Le-Guen M, Girard M, Lu Q, Rouby JJ (2010) Ultrasound assessment of antibiotic-induced pulmonary reaeration in ventilatorassociated pneumonia. Crit Care Med 38:84-92

31. Volpicelli G, Melniker LA, Cardinale L, Lamorte A, Frascisco MF (2013) Lung ultrasound in diagnosing and monitoring pulmonary interstitial fluid. Radiol Med 118:196-205

32. Zieleskiewicz L, Cornesse A, Hammad E, Haddam M, Brun C, Vigne C, Meyssignac B, Remacle A, Chaumoitre $\mathrm{K}$, Antonini F, Martin C, Leone M (2015) Implementation of lung ultrasound in polyvalent intensive care unit: impact on irradiation and medical cost. Anaesth Crit Care Pain Med 34:41-44
33. Laursen CB, Sloth E, Lassen AT, Christensen Rd, Lambrechtsen J, Madsen PH, Henriksen DP, Davidsen JR, Rasmussen F (2014) Point-of-care ultrasonography in patients admitted with respiratory symptoms: a singleblind, randomised controlled trial. Lancet Respir Med 2:638-646

34. Georgopoulos D, Xirouchaki N, Volpicelli G (2014) Lung ultrasound in the intensive care unit: let's move forward. Intensive Care Med 40:1592-1594

35. Hansen MA, Juhl-Olsen P, Thorn $S$, Frederiksen CA, Sloth E (2014) Ultrasonography-guided radial artery catheterization is superior compared with the traditional palpation technique: a prospective, randomized, blinded, crossover study. Acta Anaesthesiol Scand 58:446-452

36. ARISE Investigators, ANZICS Clinical Trials Group, Peake SL, Delaney A, Bailey M, Bellomo R, Cameron PA, Cooper DJ, Higgins AM, Holdgate A, Howe BD, Webb SA, Williams P (2014) Goal-directed resuscitation for patients with early septic shock. N Engl J Med 371:1496-1506

37. Investigators ProCESS, Yealy DM, Kellum JA, Huang DT, Barnato AE, Weissfeld LA, Pike F, Terndrup T, Wang HE, Hou PC, LoVecchio F, Filbin MR, Shapiro NI, Angus DC (2014) A randomized trial of protocolbased care for early septic shock. N Engl J Med 370:1683-1693

38. Expert Round Table on Echocardiography in ICU (2014) International consensus statement on training standards for advanced critical care echocardiography. Intensive Care Med 40:654-666 